\title{
Driving farm performance using information systems
}

\author{
C. ISAACS ${ }^{1}$ and T.A. WHITE ${ }^{2}$ \\ ${ }^{1}$ Farm ${ }^{I Q}$ Systems Ltd, 15 Allen St, Wellington 6149, New Zealand \\ ${ }^{2}$ Farm $^{I Q}$ Systems Ltd, 139 Awahou South Road, Ashhurst 4884, New Zealand \\ collier.isaacs@farmiq.co.nz
}

\begin{abstract}
Farm ${ }^{\mathrm{IQ}}$ Systems Limited was established as a Primary Growth Partnership (PGP) between the Ministry for Primary Industries (MPI), the meat processor Silver Fern Farms and Landcorp Farming Limited. Farm ${ }^{\mathrm{IQ}}$ aims to create a truly integrated value and information chain for red meat from product back to farm. The major output of this partnership is the Farm ${ }^{\mathrm{IQ}}$ System farm management software developed in New Zealand for New Zealand farmers. Hill country farmers have historically been at a disadvantage compared to their lowland counterparts in terms of the ease of quantifying farm performance. The Farm ${ }^{\mathrm{IQ}}$ System is a cloudbased tool that addresses these challenges of scale and isolation. It allows all types of red meat farmers to plan, communicate, record, analyse and report information about land, feed and animals easily and accurately.
\end{abstract}

Keywords: Farm ${ }^{\mathrm{IQ}}$ System, integration, better decisions

\section{Key messages}

- Cloud-based software for farmers to record, analyse and report information about their land, feed and animals

- Software based on an integrated value chain approach, providing objective feedback about the impact of farm management decisions on product quality

- Integration with other farm planning and financial software provides a single-entry solution to minimise duplication of on-farm data recording.

\section{Introduction}

Around half of New Zealand's drystock farms fall into the category of "hill country" or "hard hill country", according to Beef + Lamb New Zealand's Economic Service (A. Burtt pers. comm.)

To maintain sustainable growth, critical needs for hill country farming systems in the future are:

- Good market information

- Achieving greater returns through increased quality and efficiency of production

- Meeting farm assurance and regulatory requirements

- Integrated tools to support good planning and decision making

- Share information with key advisors.

New Zealand's Ministry for Primary Industries (MPI) recognises that such industry-wide farming system development goes beyond business as usual and requires significant investment and partnership with industry.

Farm ${ }^{\mathrm{IQ}}$ was established as a Primary Growth Partnership (PGP) between MPI, the meat processor Silver Fern Farms and Landcorp Farming Limited. Farm ${ }^{\mathrm{IQ}}$ aims to create a truly integrated value chain for red meat where farmers can identify management strategies that not only increase the quantity of meat produced but also its quality and therefore its value. For this to be achieved there needs to be an information system that shares data between participants along the value chain. This is the Farm ${ }^{\text {IQ }}$ System, which is cloudbased farm management computer software developed in New Zealand, for New Zealand farmers.

The Farm ${ }^{\mathrm{IQ}}$ System is a tool that sheep, beef and deer farmers can use to record, analyse and report information about their land, feed and animals. The challenges of scale, isolation and poor connectivity have been carefully considered during development, resulting in software that addresses the unique information needs of New Zealand's hill country farmers.

To support this process, Farm ${ }^{\mathrm{IQ}}$ partnered with 11 commercial sheep, beef and deer farms around the country (collectively referred as 'IQ Farms'). The IQ Farms receive a free subscription to the Farm ${ }^{\mathrm{IQ}}$ System and, where needed, have been provided with technology to capture information against land and animals. In return for the investment, the IQ Farms have conducted projects to investigate the value of measuring and monitoring paddock and animal performance, and how this can best be integrated into livestock farming systems.

\section{Method}

Each IQ Farm determined their initial farm performance. The metrics used to gauge this varied because of differences in farm system but typically involved measures of conception rates, offspring survival, animal growth rates, production per ha, farm income and expenses, and economic farm surplus. Then, often with the help of a team of expert advisors, the IQ Farmers identified opportunities for improvement in their farming system. They established projects that tested changes in management aimed at improving their key performance indices and progress their businesses. These projects involved measuring and monitoring 
using the Farm ${ }^{\mathrm{IQ}}$ system and often in combination with other technologies.

Examples of the studies conducted on the IQ Farms include:

- Objective data to help identify 'A' and 'B' breeding ewe flocks on Mangarata-Taratahi, Wairarapa

- Setting liveweight targets for ewe replacements to maximise weaning performance on White Rock Mains, North Canterbury

- Measuring for efficient lamb finishing on Ohineumeri, Hawke's Bay

- Measuring finishing deer to target a market window on Stuart, Te Anau

- Recording body condition scores at key times to monitor ewe performance on Glenaan, Rakaia Gorge

- Animal health trend reporting shows farm performance against benchmarks on Whangara Farms, Gisborne.

\section{Results}

\section{IQ Farm studies}

Objective data to help identify 'A' and ' $B$ 'breeding ewe flocks on Mangarata-Taratahi, Wairarapa

Electronic identification (EID) tags used with the Farm ${ }^{\mathrm{IQ}}$ System can make individual animal data recording easy. The history of information stored (e.g. sex, breed, birth rank, supplier, stock class, liveweights, scanning results, condition scores, feeding, health treatments, location) against EID tags in the Farm ${ }^{\mathrm{IQ}}$ System enables the farmer to make more informed decisions about which animals to keep as breeding replacements, which to mate to terminal sires and which to sell. Mangarata is a typical North Island East Coast hill country sheep and cattle breeding operation. Given the topography and climate, they only have a limited ability to finish stock prime in most years. Therefore, their emphasis for sheep is developing a breeding ewe flock with high fecundity, lamb survival and percentage of lambs killed at weaning. They run as an 'A' flock, mated to maternal sires, and a ' $\mathrm{B}$ ' flock, mated to terminal sires. They use multiple criteria for deciding which animals enter and remain in the 'A' flock. Animals are eliminated for undesirable visual traits related to nose colour, feet, wool and frame composition. Undesirable animals are also identified based on a combination of liveweight and pregnancy scanning data collected when they were hoggets and 2-tooths. Mangarata use the 'Draft List' function in the Farm ${ }^{\mathrm{IQ}}$ System to identify ewes that are above $40 \mathrm{~kg}$ liveweight at hogget mating but do not get pregnant, and that as a 2-tooth only produce a single lamb. These animals are 'black-flagged'. If they then scan as a single-bearing ewe as a 4-tooth they are either sold or in the following year are mated to a terminal sire. The Farm ${ }^{\mathrm{IQ}}$ System can also generate draft files that can be imported into weigh-scale head units, so the animals can be physically drafted quickly and easily in the yards.

\section{Breaking the cycle on White Rock Mains, North Canterbury}

White Rock Mains is a 1050 ha property in the Canterbury foot-hills, running 7500 sheep and cattle stock units for breeding and finishing. For the first 2 years of being an IQ Farm, they recorded ewe conception, lamb survival, weaning weights and growth rates as well as pasture covers in the Farm ${ }^{\mathrm{IQ}}$ System This base farm performance data showed they were overly focused on finishing lambs, to the detriment of the breeding ewe flock. After weaning in January, the best feed was being allocated to sale lambs, and breeding ewe replacements were not being grown out to their full potential. This created a negative cycle as it detrimentally affected their conception rates and the other aspects of reproductive performance - lamb survival, ewe milk production, lamb growth rates and weaning date. A detailed plan was laid out for the replacements, with target liveweights and body condition scores and close monitoring with the Farm ${ }^{\mathrm{IQ}}$ System. It was estimated (in March 2014) that if White Rock Mains can lift the breeding ewe lambing percentage and maintain weaning weight, at weaning time the lamb crop would worth be an extra \$52 224/ year in gross revenue.

\section{Measuring for efficient lamb finishing on Ohineumeri,} Hawke's Bay

Ohineumeri Station is a 1140 ha property near Waipukurau that places strong emphasis on lamb finishing. They finish 6500 home-bred lambs prime from December to April and, if the season permits, up to 3000 store lambs are bought in May and finished through winter, along with some cattle. This study found that regularly measuring animal liveweights with electronic recording equipment is key to efficient finishing on this property. Getting timely information helped them get the lambs up to slaughter weight both quickly and efficiently. By keeping a close eye on how fast animals are growing, the farmer can match feed supply with demand and reliably book kill space in advance. All lambs are EID-tagged at docking, and after weaning they are run in a 'rolling cycle' of mobs, with animals going onto a forage-crop and then sold as they reach the cut-off weight. Running all lambs over the weigh-scales and collecting information used to take a whole day but now takes about 2 hours and the farmer's use of any paper recording is minimised. As long as the comparisons are balanced without confounding effects, the FarmIQ System can quickly and accurately calculate within-year and between-year differences in performance (e.g. liveweights, growth rates, carcass 
weights) of sire genetics, suppliers or other management factors that are determined by farmers. The farmer physically runs the animals together on the farm but in the system they can be separated into reporting groups and performance differences become apparent.

\section{Targeting a market window on Stuart, Te Anau}

Stuart Farm near Te Anau runs 29000 stock units on 2800 ha and its operation includes finishing around 1700 yearling deer a year. This study showed how farmers can use more detailed analysis of individual stock performance to fine-tune finishing systems and maximise returns. For Stuart Farm this meant measuring individual liveweights of its yearling deer so they better understand which animals are making the higher value chilled market rather than the lower value post-chill season. They found that $43 \%$ of crossbred but only $30 \%$ of red stags were achieving the weight cut-off for the chilled market. Their individual animal data in the Farm ${ }^{\text {IQ }}$ System also highlighted useful management trigger points as they progressed through autumn and winter leading up to the chilled season. They found that animals above $75 \mathrm{~kg}$ by 1 May were almost certain to make the grade and should be continued to be well fed, but not excessively. Animals that were $65-70 \mathrm{~kg}$ at this time presented the greatest opportunity to get more animals into the chilled market and should be prioritised in terms of limited winter feed. Animals weighing less than $65 \mathrm{~kg}$ at this time are unlikely to make it, so their feeding should be reduced until the spring flush and then they should be fully fed, targeting the post-chill market.

The value of ewe body condition scoring on Glenaan, Rakaia Gorge

Glenaan Station is a 1035 ha high-country property in the Rakaia Gorge, running a main breeding flock of 2750 ultra-fine Merino ewes and 1500 hoggets, along with 700 Romney ewes and 160 Angus cattle. This study entailed measuring and recording individual ewe body condition scores against EID tags, to find out what effect body condition has on a range of production parameters, including conception rates, lamb survival and fleece value. As part of this, poorer condition ewes were given a higher priority for feed allocation, while ewes in better condition were given less. Ewes were body condition scored by hand at weaning, mating and shearing. It was found that knowing the average condition score of a group of Glenaan ewes enabled a accurate prediction (with 99\% reliability) of what the group's average scanning result would be. The analysis showed that raising the condition score of a lower-end ewe by 0.5 of a condition score to 3 meant that the scanning percentage would be lifted by $10 \%$ overall.
Animal health trend reporting on Whangara Farms, Gisborne

Whangara Farms runs more than 60000 stock units of sheep and cattle on multiple coastal blocks north of Gisborne. This study looked at the value of online reporting through the Farm ${ }^{\mathrm{IQ}}$ System to give Whangara management a more accurate picture of animal health trends in stock sent for slaughter at Silver Fern Farms. This showed up quite a high level of liver fluke in the Whangara cattle, compared to a national benchmark. The Whangara management said that seeing results like this clearly illustrated the situation and was "hardhitting". It also showed the spikes along the timeline when liver fluke is a worse issue. Whangara decided to do more to control fluke as a result. At the end of winter they now inject 'Ivomec Plus' into the young Friesian bulls that they buy in at 15 months and kill prime about 12 months later. 'Ivomec Plus' should kill all flukes except immature ones. It is considerably more expensive than the standard drench they had been using but the carcass defect data returned to them through the Farm ${ }^{\mathrm{IQ}}$ System, clearly showed there was an issue that needed to be addressed.

\section{Discussion}

\section{Pain points}

The IQ Farm case studies helped to identify some consistent issues when adopting a farming approach where decisions are based on objective data. These were:

- Determining the right indicators of performance for their farm system

- Determining how to measure and record without creating too much extra work

- Effectively reporting and analysing information to reach useful conclusions for decision making.

To be able to reliably and quickly collect data against individual animals, some investment in technology is required. Depending on level of sophistication, set-up costs for EID readers, electronic weigh-scales, and autodrafting animal handling equipment can cost $\$ 20000$ for sheep and potentially more for cattle. However, wellmaintained equipment will have useful life of greater than 10 years. If used well, the improved management decisions from these technologies easily compensate for the initial outlay. For example, the ability to quickly and accurately monitor ewe and lamb weights at critical times of year has led to improvements in management, flock performance and farm profitability on White Rock Mains.

\section{Future}

At the 2015 New Zealand Grassland Association conference, a North Wairarapa farmer observed, "One of the key limitations to hill country sheep and beef farming is the variation and averaging effect. Our class 
of country relies more heavily on individual farmers' experience, competence and 'gut feeling' than other classes of country..." (McKenzie 2015). In other words, hill country farmers have always been at a disadvantage compared to their lowland counterparts, when it comes to the type of data that can be collected about land and animals.

Fortunately, there is growing awareness that livestock farming is currently undergoing an information and technology revolution that will greatly help hill country farmers. Farmers like McKenzie (2015) recognise the opportunities: "The key is around focusing on technologies and advancements to bridge the gap and have hill country sheep and beef farms producing at their maximum efficiency."

The Farm ${ }^{\mathrm{IQ}}$ PGP programme is at the forefront of this revolution by delivering a farm information hub and analysis tool that:

- Identifies performance by determining best-practice management decisions for individual farms based on objective data captured at different points along the value chain

- Takes a collaborative approach across the value chain by integrating data from many sources to support farm decision making.

\section{The Farm ${ }^{\mathrm{IQ}}$ System}

The Farm ${ }^{\mathrm{IQ}}$ System makes it easier for farmers to record, analyse and report animal and land data through integration with a range of data capture devices, data suppliers and other decision support software. This makes it accessible and realistic for hill country farm businesses to use.

Specifically:

- The mobile app with online and offline capability lets farm staff record information into their farm database as they work on-farm, reducing the need for afterhours office time

- Integration with weigh-scale electronic head units enables easy data capture during stock handling activities

- Data sharing with other cloud-based software, such as Cashmanager Rural and Farmax, means farmers only enter information once for use in multiple systems.

The Farm ${ }^{\mathrm{IQ}}$ System can also integrate with processors' carcass data collection and information systems. This integration (currently only with Silver Fern Farms) provides the ability to match individual carcass performance data with data compiled when animals were live on-farm and show the impact of onfarm decisions on meat quality and yield, occurrence of disease and product defects.

For beef cattle, in addition to traditional carcass grading metrics, farmers using Farm ${ }^{\mathrm{IQ}}$ can also access 'BeefEQ' reporting. The 'BeefEQ' grading system (short for Beef Eating Quality) was developed by Silver Fern Farms to objectively and consistently identify carcasses that will give superior consumer eating outcomes. Carcasses that achieve high enough scores are graded 'Master Grade' and will be used for Silver Fern Farms' premium reserve product lines. Suppliers receive an additional per-kilogram payment for these.

Farmers can use the Farm ${ }^{\mathrm{IQ}}$ System to analyse differences in grading scores and identify the management decisions that will lead to higher value production. Farmers can also produce reports that are suitable for a range of auditing purposes related to animal health, veterinary remedies and medicine inventories, health and safety, and land and environment management.

\section{Communication is key}

While the total number of farms in New Zealand is decreasing, their size is increasing. This means more animals, more staff and more outside contractors and possibly off-farm investors and advisers. Effective communication of plans and day-to-day tasks can be challenging and the costs of miscommunication significant. The Farm ${ }^{\mathrm{IQ}}$ System has been designed to help in this regard too: farmers can grant access to anyone involved in the farm business, tasks can be assigned to specific people and liaison can occur via the Farm ${ }^{\mathrm{IQ}}$ mobile app. This eases communication and assists farm organisation, and over time supports farmers and their advisers gaining a deeper insight into key farm drivers and associated opportunities.

\section{ACKNOWLEDGEMENTS}

Farm ${ }^{\mathrm{IQ}}$ would like to acknowledge all the New Zealand farmers who have assisted with the development of the Farm ${ }^{\mathrm{IQ}}$ System over the past 5 years and in particular the members of the Technical Advisory Group and the IQ Farms group.

\section{REFERENCES}

McKenzie, D. 2015. Farming into the future innovation technology and efficiency. Journal of New Zealand Grasslands 77: 61-63.

Case study - Animal health reports spur actions. September 2014. Farm ${ }^{\mathrm{IQ}}$ website: http://www. farmiq.co.nz/

Case study - Breaking the cycle. March 2014. Farm ${ }^{\mathrm{IQ}}$ website: http://www.farmiq.co.nz/

Case study - Targeting a market window. June 2014. Farm ${ }^{\mathrm{IQ}}$ website: $\mathrm{http}: / / w w w . f a r m i q . c o . n z /$

Measuring ewes at weaning pays off. December 2014. Farm ${ }^{\mathrm{IQ}}$ website: http://www.farmiq.co.nz/

Measuring liveweights key to efficient finishing. December 2014. Farm ${ }^{\mathrm{IQ}}$ website: http://www.farmiq. co.nz/ 